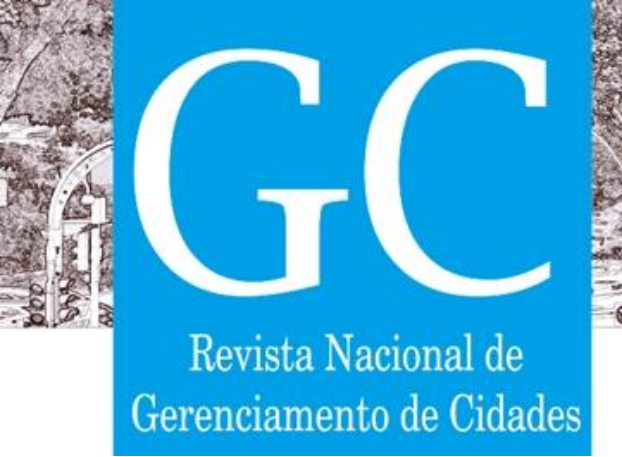

\title{
O Dia em que a Terra Parou: a vida nas metrópoles em tempos de isolamento e distanciamento social
}

The Day the Earth Stopped: life in the metropolis in times of isolation and social distance

El Día que la Tierra se Detuvo: vida en la metrópoli en tiempos de aislamiento y distancia social

Douglas Gallo

Professor Mestre, IFSP, Brasil Doutorando em Urbanismo, FAU/PROURB/UFRJ, Brasil douglas.luciano@yahoo.com.br

\section{Wanderson da Silva Augusto}

Administrador, INESP, Brasil Tecnólogo em Gestão de Recursos Humanos, Brasil wsacontatos@gmail.com

\section{Valéria Cristina Lopes Gallo}

Enfermeira CHC/UFPR, Brasil Mestranda em Enfermagem (profissional), UFPR, Brasil. valeria.gallo@hotmail.com 


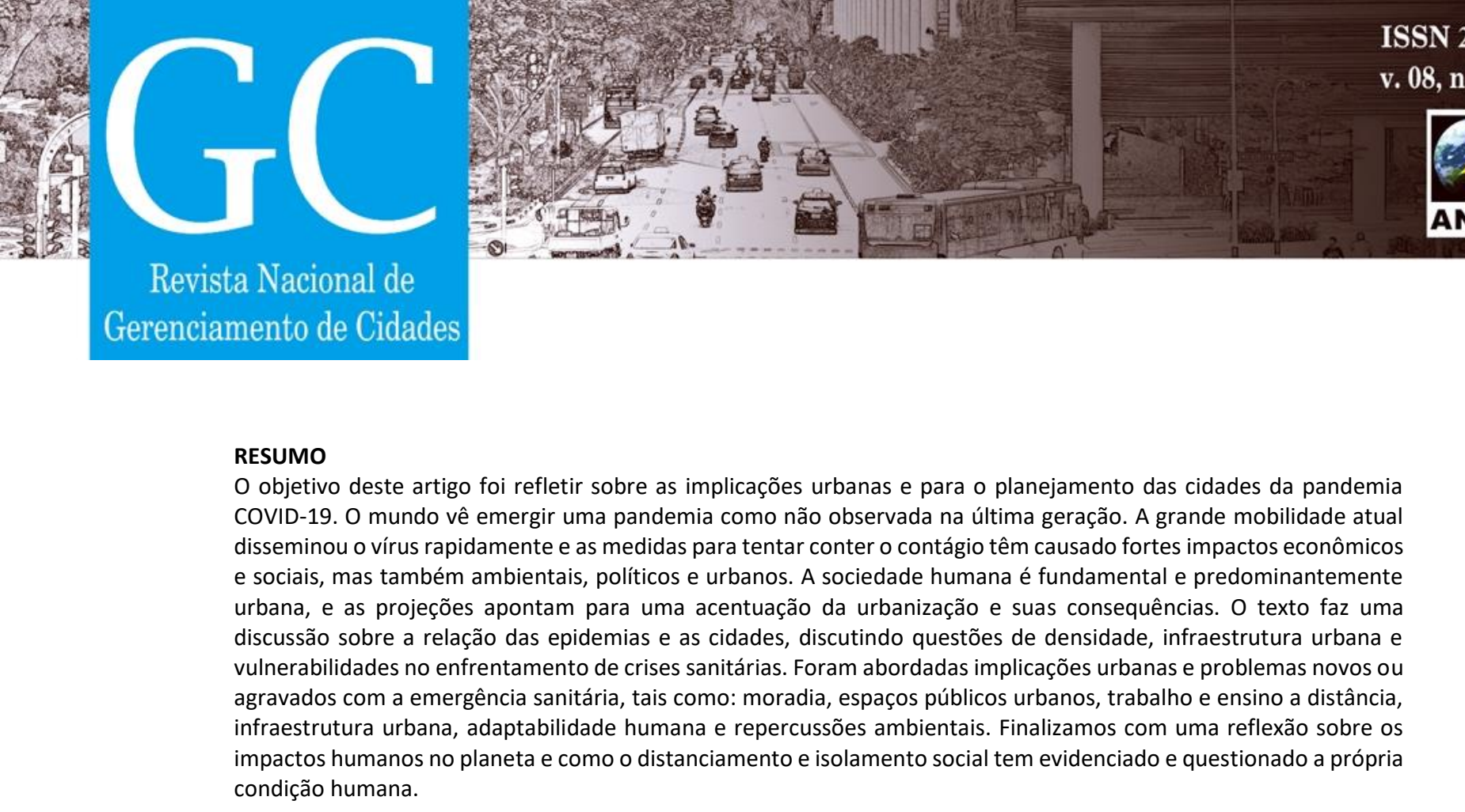

PALAVRAS-CHAVE: Planejamento urbano. Covid-19. Saúde urbana.

\section{ABSTRACT}

This study aimed to reflect on the urban implications and the implications for city planning in the COVID-19 pandemic. The world sees a pandemic emerging as not seen in the last generation. The current great mobility spread the virus quickly and the measures to try to contain the contagion have caused strong economic and social impacts, but also environmental, political and urban impacts. Human society is fundamentally and predominantly urban society, and projections show an increase in urbanization and its consequences. The text discusses the relationship between epidemics and cities, discussing issues of density, urban infrastructure and vulnerabilities in facing health crises. Urban implications and new or aggravated problems with the sanitary emergency were addressed, such as: housing, urban public spaces, distance work and learning, human adaptability and environmental repercussions. We end with a reflection on the human impacts on the planet and how the social distancing and social isolation has highlighted and questioned the human condition itself.

KEYWORDS: Urban Planning. Covid-19. Urban health.

\section{RESUMEN}

El propósito de este artículo era reflexionar sobre las implicaciones urbanas y la para la planificación de las ciudades de la pandemia COVID-19. El mundo ve emerger una pandemia que no se vio em la última generación. La gran movilidad actual propagó el virus rápidamente y las medidas para tratar de contener el contagio han causado fuertes impactos económicos y sociales, pero también impactos ambientales, políticos y urbanos. La sociedad humana es fundamental y predominantemente urbana, y las proyecciones apuntan a un aumento de la urbanización y sus consecuencias. El texto discute la relación entre epidemias y ciudades, discute temas de densidad, infraestructura urbana y vulnerabilidades para enfrentar crisis de salud. Se abordaron las implicaciones urbanas y los problemas nuevos o agravados con la emergencia sanitaria, tales como: vivienda, espacios públicos urbanos, trabajo y educación a distancia, infraestructura urbana, adaptabilidad humana y repercusiones ambientales. Concluimos con una reflexión sobre los impactos humanos en el planeta y como la distancia y el aislamiento social han resaltado y cuestionado la propia condición humana.

PALABRAS CLAVE: Planificación urbana. Covid-19. Salud urbana. 



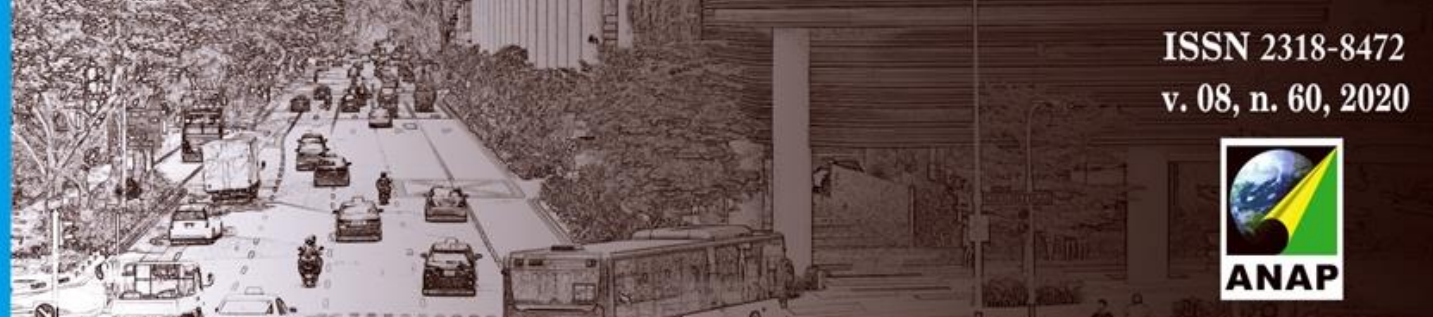

Revista Nacional de

Gerenciamento de Cidades

(BAUDELAIRE, 1996) e a atitude blasé (SIMMEL, 1967). O grande diferencial desta vida urbana, especialmente nas grandes cidades, é o anonimato e a diversidade, de pessoas e culturas. A concentração e densidade urbana são características essenciais para a vitalidade e urbanidade, porém, em tempos de pandemia, traz questionamentos importantes.

O urbano, como realidade e objeto de estudo, em sua dimensão e complexidade, tem sua discussão ampliada e enriquecida com as contribuições de diferentes áreas, para além da disciplina do urbanismo (LEME, 2003). Diversas leituras podem ser feitas da cidade: como um discurso pela semiologia (SANTAELLA, 2016); como manifestação de práticas culturais e mercadológicas (SARLO, 2014; HERCE, 2015); como processo histórico (ARGAN, 2015; BRESCIANI, 2018); como espaço de produção e reprodução capitalista (CARLOS et al, 2015; HARVEY, 2005); ou como palco para conflitos sociais e sociabilidades (HARVEY, 2014; FRÚGOLI JUNIOR, 2007). A multiplicidade de olhares enriquece e valoriza as análises do fenômeno urbano (BRESCIANI, 2018), a estas abordagens, há a necessidade de adicionar a discussão sobre a dimensão humana das cidades (JACOBS, 2009; GEHL, 2012, 2018).

Dentro dessa realidade urbana, complexa e irreversível e em meio a uma crise sanitária mundial, o presente artigo objetiva refletir sobre as implicações que a pandemia COVID-19 têm sobre as cidades, especialmente considerando os espaços públicos e planejamento urbano.

\section{PANDEMIAS E CIDADES}

Grandes cidades, densas, interativas e conectadas parecem ser o campo perfeito para a disseminação de epidemias ou pandemias. A proximidade social presente nos ambientes urbanos ao mesmo tempo que facilita a disseminação de doenças infectocontagiosas, também dificultam seu enfrentamento e resposta (LING, 2020).

De acordo com Li, Richmond e Roehner (2018), não há apenas uma relação entre a escala da densidade populacional e o tamanho de epidemias de influenza, por exemplo, mas também um profundo impacto na evolução das epidemias e na recuperação pós surtos, em aglomerações urbanas, quanto maior sua densidade. Os dados sugerem que quanto maior a densidade populacional, tanto maior será a gravidade da epidemia e sua mortalidade (mesmo que a correlação no estudo tenha sido fraca, foi claramente definida). A falta de imunidade nas populações, aliada a uma alta densidade populacional são responsáveis por picos de casos grandes e estreitos, levando ao colapso dos sistemas de saúde.

Alguns estudos sugerem que a densidade não teria muito efeito, porém são realizados comparando países e não cidades, o que pode mascarar diferenças importantes, uma vez que o território de um país abrange diferenças enormes de densidade populacional, entre cidades, e territórios urbanos e rurais. A densidade em si não determina a facilidade com que uma infecção se espalha, os problemas surgem quando as populações se tornam tão densas a ponto de causar superlotação. A superlotação está normalmente relacionada a reduções na qualidade de vida e precariedade de saneamento básico, elevando a taxa de transmissão nestas áreas. 


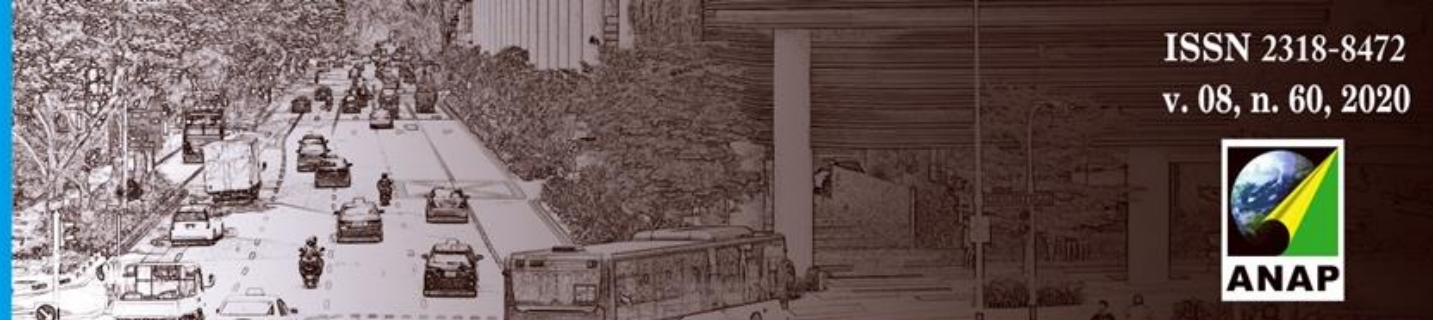

Revista Nacional de

Gerenciamento de Cidades

Ao estudar o sarampo, Tarwater (1999) demostrou resultados que sustentam a ideia de que o número de novos casos infecciosos estaria relacionado à distribuição de contatos suscetíveis, demostrando grandes diferenças em populações com densidades diferentes. $\mathrm{O}$ termo "contato com indivíduos suscetíveis" significa um contato suficiente entre duas pessoas para que a doença passe de uma pessoa infecciosa para uma pessoa suscetível. Ao explorar a relação entre a densidade populacional, dada uma taxa de imunidade de rebanho ${ }^{1}$ na população, considerando os contatos suscetíveis, o estudo mostrou grandes diferenças nas medidas epidêmicas entre populações com densidades diferentes.

As relações entre urbanismo e cidades são conhecidas de longa data (GALLO e BESSA, 2018), e em diversos momentos históricos as cidades se viram flageladas por epidemias (Quadro 1), especialmente na Europa Medieval, mas também no período pós-industrial, desenvolvendo-se um tipo de urbanismo reformista, chamado de sanitarista (GONÇALVES, 2014; MELLO, 2014). No Brasil, diversos planos urbanos surgiram para melhorar a salubridade do espaços urbano (Figura 2), destacando-se neste cenário a reforma urbana realizada no Rio de Janeiro por Pereira Passos e o Plano de Avenidas para São Paulo, de Prestes Maia, além de diversos planos e projetos do engenheiro Saturnino de Brito (ANELLI, 2007; MÜLLER, 2002; BERTONI, 2015; TOCHETTO, 2015).

Quadro 1: Grandes epidemias urbanas
\begin{tabular}{|l|c|c|}
\hline \multicolumn{1}{|c|}{ Epidemia } & Data & Vítimas fatais \\
\hline Peste de Justiniano & Séc. VI (541) & 25 a 50 milhões \\
\hline Peste Negra (Bulbônica) & Séc. XIV (1343) & 75 a 200 milhões \\
\hline Peste Russa & Séc. XIX (1889) & 1,5 milhão \\
\hline Gripe Espanhola & Séc. XX (1918) & 50 a 100 milhões \\
\hline Gripe Asiática & Séc. XX (1957) & 2 milhões \\
\hline Gripe de Hong Kong & Séc. XX (1968) & 3 milhões \\
\hline SARS (Síndrome Respiratória Aguda Grave) & Séc. XXI (2003) & 774 \\
\hline Gripe Aviária* & Séc. XXI (2004) & 300 \\
\hline Gripe H1N1 (Gripe Suína) & Séc. XXI (2009) & 284 mil \\
\hline MERS (Síndrome Respiratória do Oriente Médio) & Séc. XXI (2012) & 858 \\
\hline Covid-19** & Séc. XXI (2020) & 320 mil \\
\hline
\end{tabular}

* O número de óbitos foi muito inferior aos demais surtos, mas mesmo assim, para frear a proliferação foram mortos 1,5 milhão de aves

** número de mortes aproximado até o fechamento do artigo.

A disseminação de epidemias no espaço urbano, em territórios densos como assentamentos informais (favelas) e moradias coletivas, como os cortiços, podem justificar políticas de eliminação desses espaços e retiradas de populações carentes de seu habitat e de áreas valorizadas da cidade. Durante a primeira metade do século XIX violentas epidemias de cólera e febre amarela flagelaram o Novo e o Velho Mundo, enquanto o Brasil ostentava a reputação de salubridade, ficando livre das duas epidemias mais aterrorizantes da História. Porém, no verão

\footnotetext{
${ }^{1}$ Imunidade de rebanho ou imunidade coletiva é a resistência de um grupo ou população à introdução e disseminação de um agente infeccioso. Isso ocorre quando existir na população uma elevada proporção de pessoas vacinadas.
} 


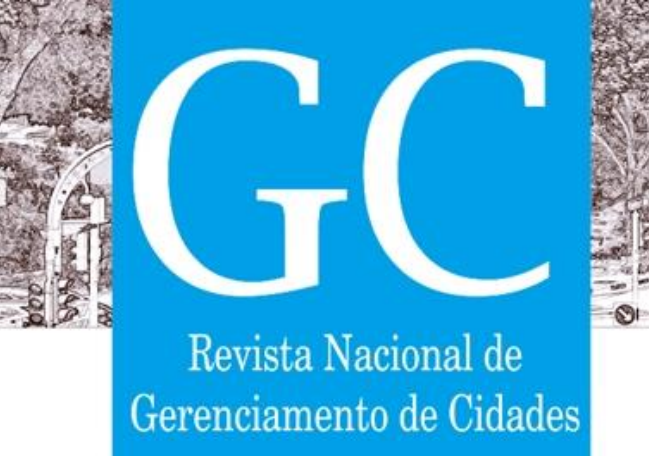

de 1849-1850 a febre amarela é reintroduzida no Brasil, reaparecendo regularmente, até que no final do século são exterminados os cortiços na cidade do Rio de Janeiro, com o propósito de promover a salubridade urbana (BENCHIMOL, 1994; CHALHOUB, 2017).

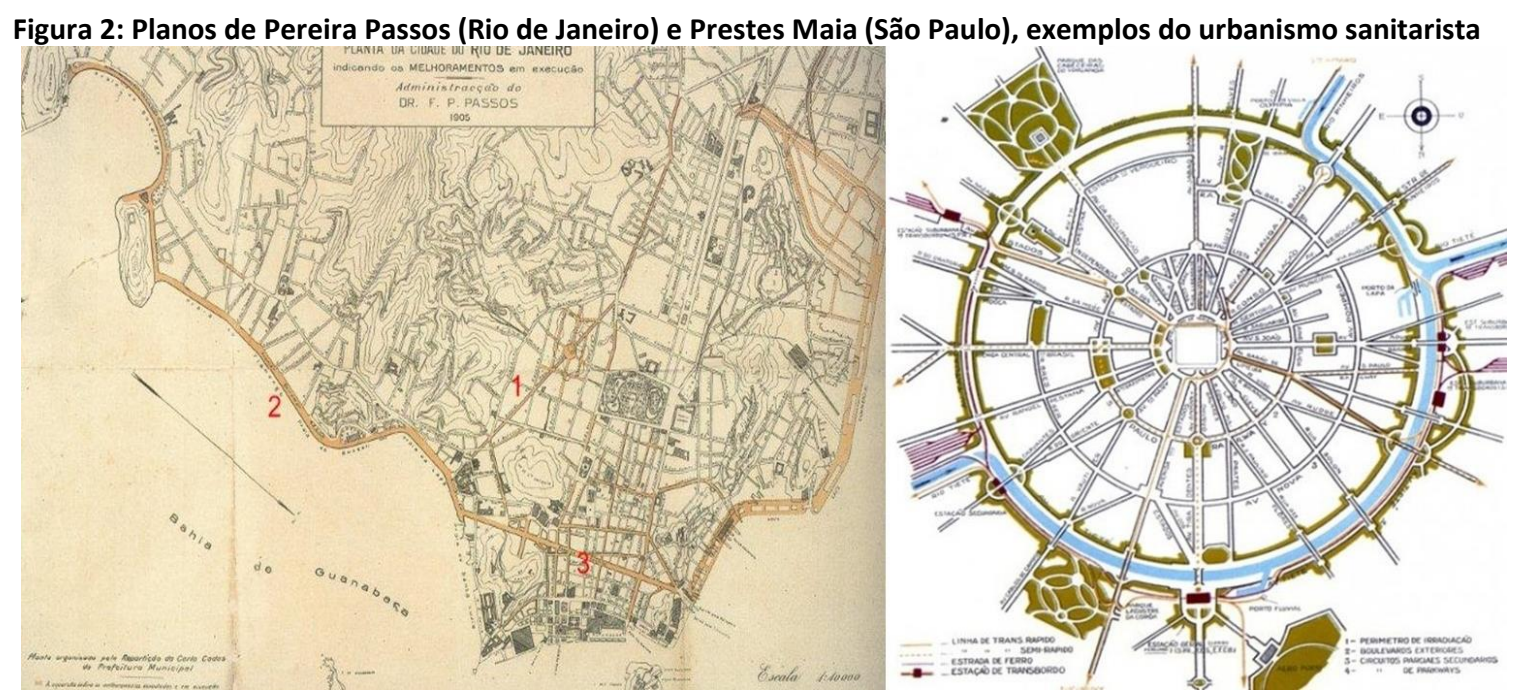

Fonte: Portal Aquitetonico, 2018; Anelli, 2007

Assentamentos informais, como as favelas nos países do sul global, como o Brasil, tem uma vulnerabilidade econômica muito grande, o que torna qualquer resposta a pandemias, como a COVID-19, um desafio ao reconhecimento da sobrevivência desses segmentos da população urbana (CORBURN et al, 2020).

\section{COVID-19}

A Organização Mundial da Saúde (OMS) foi informada de 44 casos de pneumonia de etiologia microbiana desconhecida associada à cidade de Wuhan, província de Hubei/China, em 31 de dezembro de 2019. A maioria dos pacientes relatou uma ligação com um grande mercado de frutos do mar e animais vivos (Mercado de frutos do mar da China do Huanan). A OMS anunciou que um novo coronavírus havia sido detectado em amostras colhidas nesses pacientes, já em 07 de janeiro de 2020 as autoridades chinesas o identificaram, e os testes de laboratório descartaram ser o coronavírus da síndrome respiratória aguda grave (SARS-CoV), da síndrome respiratória do Oriente Médio (MERS)-CoV, da influenza, da influenza aviária e outros patógenos respiratórios comuns. Quando sua sequência genética foi desvendada, observou-se $70 \%$ de semelhança com o agente causador do SARS - Síndrome Respiratória aguda Grave - (SARS-CoV), porém menos letal, embora com um contágio maior.

Desde então, o surto aumentou rapidamente, com a OMS declarando uma emergência de saúde pública de interesse internacional em 30 de janeiro de 2020 e depois declarando-a, formalmente como uma pandemia em 11 de março de 2020 (Figura 3). O surto se espalhou rapidamente de uma única cidade na China para toda a região e para todo o país em apenas 30 dias. 0 número de casos e mortes superou o número de casos registrados no surto de 2002-2003 de síndromes 


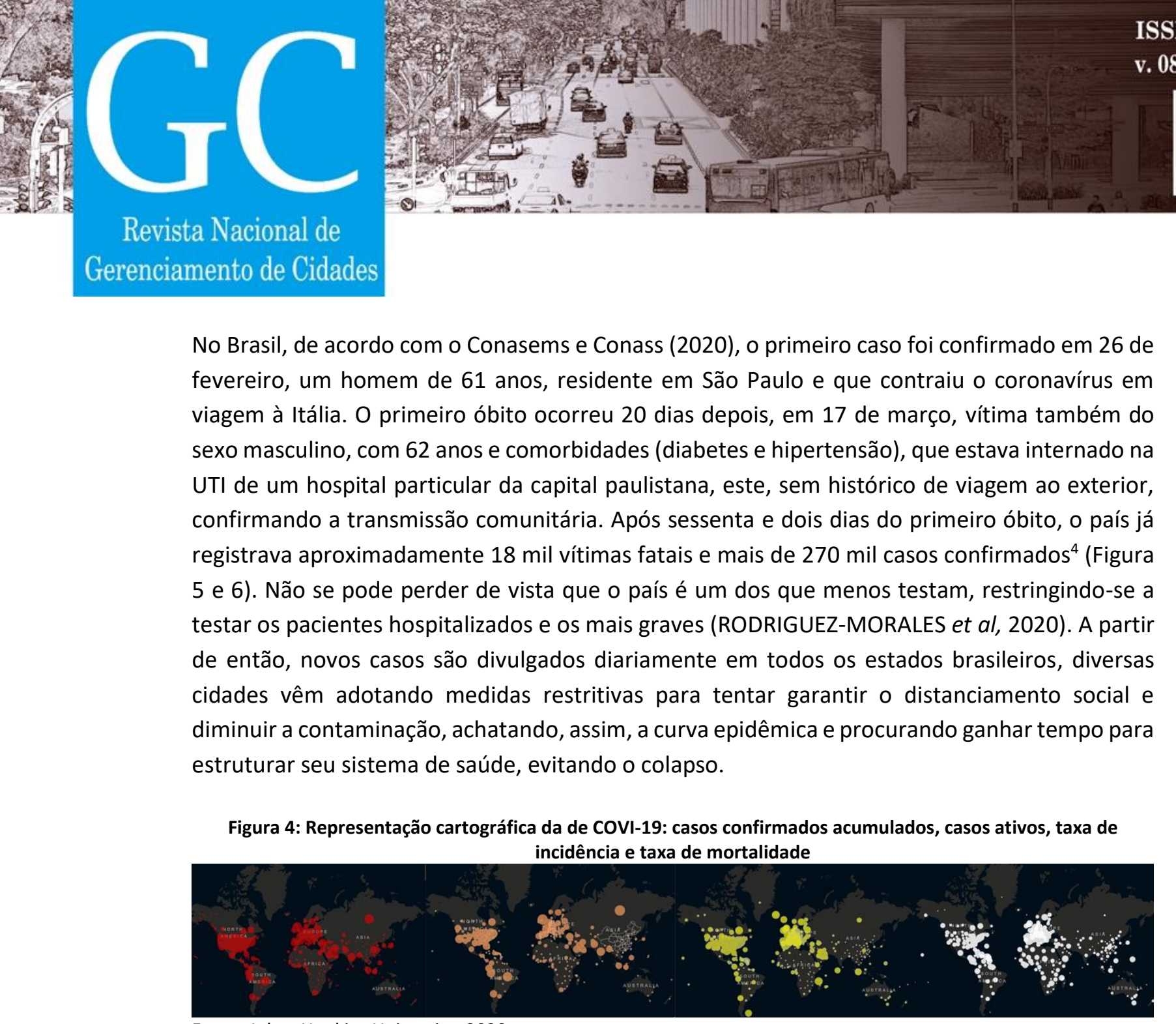

Fonte: Johns Hopkins University, 2020

Obs.: Vermelho - total de casos confirmados; Salmão - Total de casos ativos; Amarelo - taxa de incidência; Branco Taxa de mortalidade

\footnotetext{
${ }^{4}$ Dados consolidados até 19 de maio de 2020.
} 


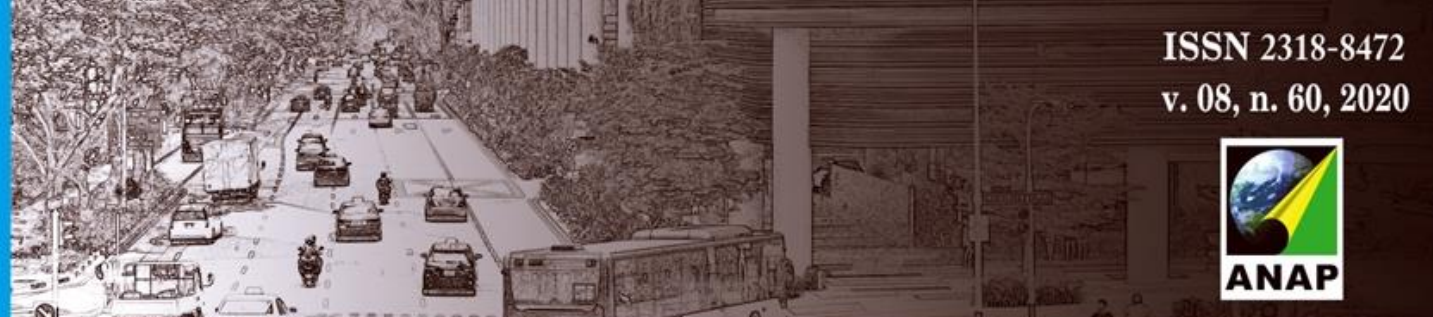

Revista Nacional de

Gerenciamento de Cidades

perspectiva transdisciplinar. A vulnerabilidade e os processos de vulnerabilização compreende que sob contextos vulneráveis, determinados territórios e populações possuem ciclos de perigo intensificados. A Figura 7, sintetiza um estudo da Fiocruz, apresentando as regiões com maior vulnerabilidade durante a pandemia COVID-19.

Quadro 2: Relação das nações mais desiguais do mundo, segundo o coeficiente de Gini e IDH, 2017

\begin{tabular}{|c|c|c|c|c|c|}
\hline & País & Continente & Coeficiente Gini & IDH & Posição IDH \\
\hline 10 & África do Sul & África & 63,0 & 0,705 & 113 음 \\
\hline 20 & Namíbia & África & 59,1 & 0,645 & 1300 \\
\hline 3응 & Zâmbia & África & 57,1 & 0,591 & $143 ㅇ$ \\
\hline 40 & República Centro-Africana & África & 56,2 & 0,381 & 188 음 \\
\hline 50 & Lesoto & África & 54,2 & 0,518 & 1640 \\
\hline 60 & Moçambique & África & 54,0 & 0,446 & 180 은 \\
\hline 70 & Brasil & América do Sul & 53,3 & 0,761 & 790 \\
\hline 80 & Botsuana & África & 53,4 & 0,728 & 940 \\
\hline 9응 & Suazilândia & África & 51,5 & 0,608 & 1380 \\
\hline 10 은 & Santa Lúcia & América Central & 51,2 & 0,745 & 89 응 \\
\hline
\end{tabular}

Moradias irregulares, assentamentos informais, famílias inteiras vivendo em espaços reduzidos, sem saneamento básico e infraestrutura mínima para uma moradia digna, é a realidade de grande parte da população brasileira. No Brasil os assentamentos irregulares recebem diversos nomes: favelas, invasões, grotas, baixadas, comunidades, vilas, ressacas, loteamentos irregulares, mocambos, palafitas etc. Segundo o IBGE, 6\% da população brasileira reside em favelas, num total de 6.329 aglomerados subnormais espalhados por 323 municípios. Embora $6 \%$ possa parecer um número baixo, equivale a 11.425 .644 pessoas, equivalendo a $5,5 \%$ do total de municípios brasileiros, ou 3.224.529 de residências (IBGE, 2016). Importante ressaltar que estas são partes da cidade, territórios que demandam políticas públicas especiais.

\section{IMPLICAÇÕES URBANAS}

Umas das implicações mais imediatas e preocupantes de uma crise sanitária e econômica como a que se vive com a COVID-19 está relacionada às moradias precárias (Figura8). Corburn et al (2020), reconhecem que em favelas urbanas, a atividade econômica informal e as microempresas são fontes econômicas importantes e que qualquer resposta à COVID-19 deveria equilibrar o bem-estar econômico e a mitigação da epidemia. Os moradores de assentamentos urbanos informais, normalmente dependem de fortes conexões sociais para sobreviver, dependendo do trabalho diário para a própria alimentação, utilização de crédito de um vendedor local ou prestadores de cuidados infantis confiáveis, apenas para citar alguns. Desta forma, medidas de auxílio a esta população vulnerável deveriam ser adotadas pelos governos. Outro aspecto relevante é o do distanciamento social, em residências com espaços mínimos, sem ventilação e condições ambientais mínimas de conforto, como essa população poderia fazer um isolamento e distanciamento adequado? Nestes assentamentos, como o espaço intradomiciliar muitas vezes é limitado e densamente ocupado, o "espaço público" torna-se 


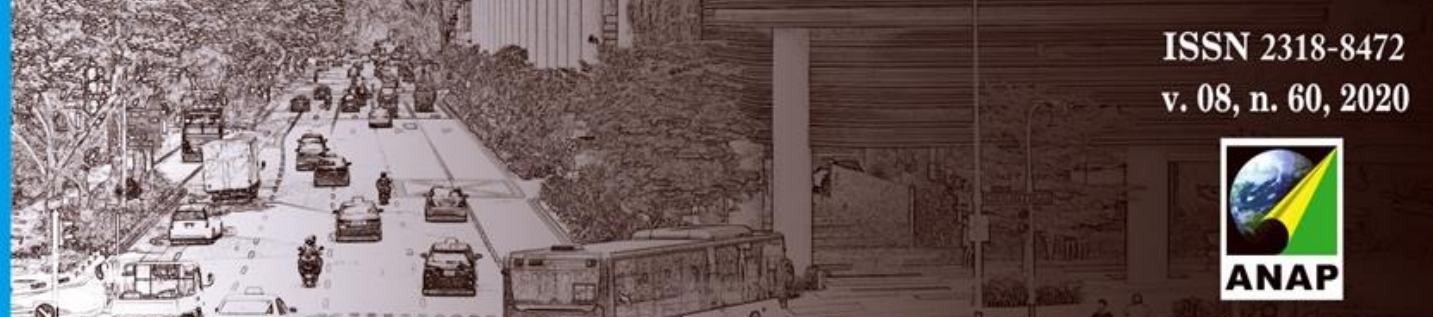

Revista Nacional de

Gerenciamento de Cidades

civilidade e urbanidade, tem sido questionada (SENNETT, 2014; BAUMAN, 2001; CALLIARI, 2018; GEHL, 2013).

Militamos por espaços urbanos mais humanos, vivos, afeitos aos encontros, e neste momento os pouco que existem, as calçadas e praças, parques e largos, esvaziados (Figura 8) nos mostram como o importante nas cidades é a dimensão humana (GEHL, 2013, 2018). Cenas que nos remetem ao filme "Ensaio sobre a cegueira", dirigido por Fernando Meirelles em 2008, e ao romance homônimo de Jose Saramago, de 1995.

Figura 9: Imagens das vias esvaziadas em São Paulo, Brasil, relembram cenas do filme "Ensaio sobre a Cegueira", primeira imagem

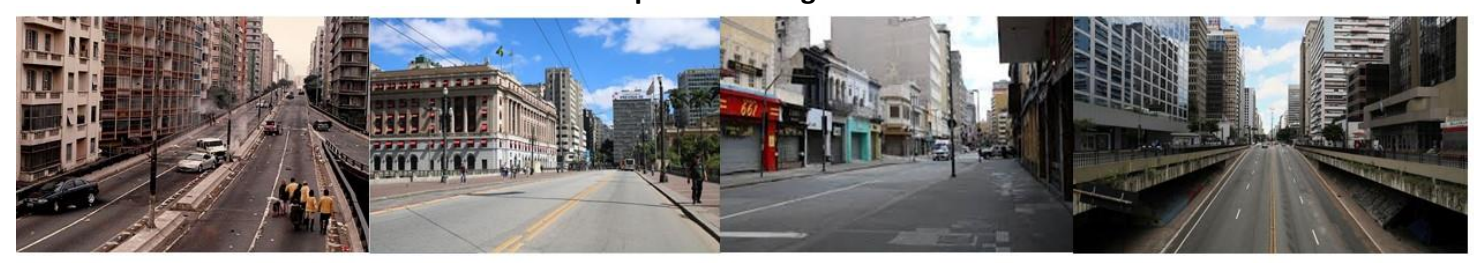

Fonte: Google images, 2020

Um problema recorrente no Brasil, mas que também se evidencia em outros países, é a politização da pandemia, uma questão sanitária, global e que deveria conglomerar todos os esforços em prol de uma solução comum, tem sido objeto de disputas com fins eleitorais, polarizando ainda mais a opinião e as políticas públicas.

Por outro lado, evidenciou-se a incrível capacidade de adaptação dos seres humanos, o "home office" a educação à distância, e todas os desafios que trouxeram, de ordem social, econômica e tecnológica, evidenciaram grande adaptabilidade da população. Porém, novamente os mais vulneráveis são os mais prejudicados, evidencia-se as desigualdades históricas. Como trabalhar ou estudar em casa, quando a moradia muitas vezes não oferece condições minimamente dignas (BRASIL, 2013). Quando há diversos membros da família dividindo o mesmo espaço, quando a infraestrutura é precária, não se tem acesso à internet, ou a banda larga não suporta a sobrecarga de todos utilizando ao mesmo tempo? Se falta computador para realizar essas tarefas e o número de brasileiros com acesso a internet corresponde a menos da metade da população, 49,8\% ou 102,1 milhões de pessoas (IBGE, 2016).

Outros aspectos positivos foram, a solidariedade e o resgate da humanidade, que pode ser sentida e observada em ações sociais e no sentimento de falta de contato social, ainda que existam pessoas mal intencionadas, empresas subindo o preço de gêneros de primeira necessidade, como higiene e alimentação. Em relação à questão ambiental, as cidades apresentaram queda na poluição atmosférica, e diminuição dos engarrafamentos, os famosos canais de Veneza, na Itália, sem turistas ficaram com águas mais claras e nítida.

Em São Paulo, por exemplo, dados mostram que a concentração máxima de monóxido de carbono foi de 1,0 ppm (partes por milhão) na estação de aferição da Marginal Tietê - Ponte dos Remédios, contra padrão de 9 ppm. Em Calcutá, Índia, um estudo encontrou variação 


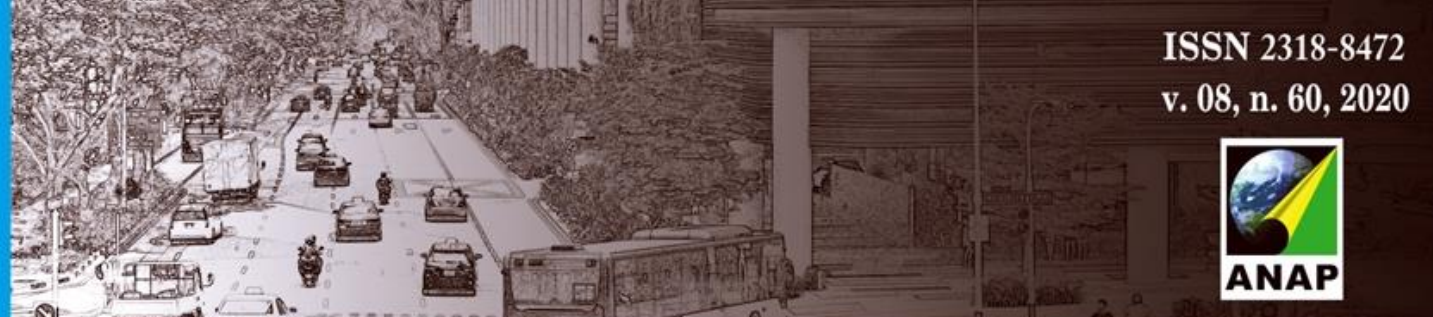

Revista Nacional de

Gerenciamento de Cidades

significativa nos níveis de dióxido de carbono pré-pandemia e durante o bloqueio realizado na cidade com fechamento completo de indústrias, transportes, mercados, shoppings, obras etc. (MITRA et al, 2020). Não é novidade que as ações antrópicas e a forma como o ser humano tem modificado seu habitat são responsáveis por diversas alterações climáticas e ambientais, o que o isolamento social e a quarentena instituída em tantas cidades nos faz pensar, é quão bom para o planeta pode ser um distanciamento do humano.

\section{CONSIDERAÇÕES FINAIS}

Questionamo-nos: "será que a sociedade como a conhecemos não é a origem das crises sanitárias, sociais, ecológicas e econômicas?"

As crises que estão se instaurando na atualidade deve nos fazer refletir, especialmente sobre o modo como pensamos, projetamos e planejamos nossas cidades, afinal, é o nosso habitat por excelência. Falamos em crise pois o que se observa é primeiramente uma crise de saúde, e a preservação da vida, como primeiro e fundamental direito humano deve ser resguardada. Mas junto se instaura a crise econômica, decorrente da diminuição do PIB, mas que deve ser questionada, até que ponto o desenvolvimento deve estar atrelado sempre e exclusivamente ao crescimento? Nunca à redistribuição? Esse questionamento é importante, pois o discurso em voga atualmente é o da falácia do desenvolvimento sustentável, e dizemos falácia, porque o desenvolvimento, tal como é concebido hoje, baseado numa sociedade de consumidores e na acumulação sem fim, nunca será sustentável.

Podemos pensar em tantas outras crises, novas ou revividas com a pandemia, a crise laboral, com a diminuição e precarização do trabalho assalariado, está não é nova, mas tomará forte impulso. O trabalho e a educação a distância vêm tornar o trabalhado fiel "escravo" do serviço, disponível 24 horas, 7 dias na semana, pelo celular e pelas reuniões virtuais. A educação, especialmente a particular tornando-se cada vez mais uma mercadoria. A crise políticopartidária, a crise ecológica e ambiental, a crise do homem público e da urbanidade, a crise da moradia e dos direitos urbanos, a crise existencial de uma sociedade que busca seu rumo, num mundo cada vez mais conectado, urbanizado, empilhado e entulhado (favelas, prisões), cada nova doença infecciosa que surge, salta para humanos (vulnerabilidades aumentam).

\section{REFERÊNCIAS BIBLIOGRÁFICAS}

ANELLI, R. Redes de mobilidade e urbanismo em São Paulo. Das radiais/perimetrais do Plano de Avenidas à malha direcional PUB. Arquitextos, 07(082.00), 2007. Disponível em:

<https://www.vitruvius.com.br/revistas/read/arquitextos/07.082/259>, acesso em 15 abr. 2020.

ARGAN, G. C. História da arte como história da cidade. São Paulo: Martins Fontes, 2005.

BARATA, R. B. Iniquidade e saúde: a determinação social do processo saúde-doença. Revista USP, 51: 138-145, 2001. 
